\title{
PAIN AS A MAJOR CAUSE OF POSTOPERATIVE NAUSEA
}

\author{
R. ANDERSEN AND K. KROHG *
}

Postoperative NAUSEA AND vomiring have numerous causes. The opiates are often cited as a major provoking factor. ${ }^{1,2}$ Pain on the other hand is not mentioned as a cause of nausea. It is the clinical impression of many doctors and recovery room nurses that people in pain are often nauseated and that proper relief of pain, even by opiates, will often relieve nausea and seldom provokes it. This impression has been indirectly supported in an earlier investigation. ${ }^{3}$ The present study was designed to elucidate further the possible connection between pain and nausea in the early postoperative period, and the effects of opiates.

\section{METHODS}

The study includes 104 patients who had either upper abdominal (80), or lower abdominal (24), operations. The patients were aged 18 to 89 years with a mean age of 60 years. Sixty-seven patients were women and 37 were men.

Premedication was with morphine and hyoscine, except for 27 patients over the age of 75 years who received meperidine and atropine 45 minutes before operation.

All patients were induced with thiopentone 200 to $400 \mathrm{mg}$ intravenously and their tracheae were intubated after relaxation with pancuronium bromide 0.1 $\mathrm{mg} / \mathrm{kg}$. Balanced anaesthesia was maintained with oxygen and nitrous oxide in a 1:3 ratio supplemented with small intravenous doses of fentanyl (0.1-0.4 mg). Half the patients were also given droperidol 2.5 to $7.5 \mathrm{mg}$ during the early part of the anaesthesia.

All patients were observed overnight in the postoperative ward. The patients were allocated at random to receive either morphine $4 \mathrm{mg}$ or ketobemidone $2 \mathrm{mg}$ intravenously whenever they complained of pain.

Only one type of analgesic drug was used in the same patient. The observation period varied between 12 and 24 hours. A separate report sheet was made out for each patient. The intensity of pain (severe, moderate or slight) was noted as well as the presence or absence of nausea or vomiting before the analgesic was given. Ten minutes after the intravenous opiate injection, at the time of maximal effect, ${ }^{4}$ the patient was again questioned as to the presence or absence of pain and nausea.

If the patient was still in severe or moderate pain after the first analgesic injection, an additional dose of half the initial dose, was given immediately and pain and nausea were again evaluated after 10 minutes. The sensory level was also noted after each opiate injection to ensure that the patient was not too heavily sedated, but still responding adequately when questioned.

'Aker Sykehus, Oslo 5, Norway. 
TABLE I

$\left.\begin{array}{lcc}\hline \multicolumn{1}{c}{\begin{array}{c}\text { Effects of } \\ \text { opiates }\end{array}} & \begin{array}{c}\text { Number of } \\ \text { observations }\end{array} & \% \text { of total } \\ \hline \begin{array}{l}\text { Complete relief of } \\ \text { pain and nausea }\end{array} & 78 & 68.5 \\ \begin{array}{l}\text { Pain greatly reduced. } \\ \text { Nausea relieved }\end{array} & 13 & 11.5\end{array}\right\}$

Effect of intravenous morphine or ketobemidone in 114 episodes of simultaneous nausea and pain.

\section{RESULTS}

An average of six intravenous doses of analgesic were needed to relieve pain during the observation period, not counting supplementary doses given 10 minutes after the initial dose when necessary.

The number of doses of analgesic given was the same whether the patients were nauseated or not, and there was no difference in pain relief or duration of effect between the two opiates used.

A total of 294 morphine injections were given to 49 patients. On ten occasions the intravenous morphine, while making the patients pain free, induced nausea, an incidence of 3.4 per cent. These ten episodes of provoked nausea appeared in seven different patients ( 14 per cent of patients) given morphine. All these patients were given the same morphine dose on at least two other occasions during the observation period without provoking nausea.

A total of 61 patients ( 58.6 per cent) complained of nausea on one or more occasions postoperatively and 10 were vomiting. These 61 patients required a total of 363 opiate injections during the observation period. Prior to 114 of these injections the patients were complaining of nausea as well as pain. On 78 occasions the opiate relieved the nausea as well as the pain. On a further 13 occasions pain was reduced from severe to slight and the nausea disappeared.

Complete pain relief without simultaneous relief of nausea was unusual. (Table I). Half of the patients who had inadequate pain relief and continued nausea after the first analgesic injection were relieved of both complaints after a supplementary dose of opiate. Heavy sedation cannot explain the findings. All patients gave adequate verbal responses when questioned at the time of maximal opiate effect. The use of droperidol during the early part of anaesthesia had no influence on the postoperative incidence of nausea.

Only 6 patients (10\%) complained of postoperative nausea without accompanying pain.

\section{Discussion}

An $\alpha$-adrenergic mechanism in the central nervous system stimulating nausea and vomiting is suggested by Jenkins and Lahay. ${ }^{5}$ They also refer to the fact that 
some general anaesthetic agents increase circulating catecholamine levels and are associated with a high incidence of postoperative vomiting. Nausea is a major limiting factor in the treatment of Parkinsonism with levodopa. ${ }^{6}$ The active metabolite dopamine is an $\alpha$ - and $\beta$-adrenergic stimulator. Trauma and pain increase the levels of circulating catecholamines. It is a common finding that injured patients exhibit nausea as well as pain.

The correlation between pain and nausea is also apparent when opiates used during anaesthesia are reversed postoperatively with an excessive dose of naloxone. Naloxone itself has no emetic properties. ${ }^{7}$

Adequate reversal with naloxone re-establishes spontaneous ventilation but leaves the patient pain free and uncomplaining. An overdose of naloxone gives abrupt return of pain and often provokes nausea and vomiting as well. ${ }^{8}$

While nausea has numerous causes it seems reasonable to assume that pain is a major but often forgotten cause. Nausea is usually present before any postoperative opiate medication has been given and seldom appears as the result of such medication.

The patients were questioned directly about symptoms of nausea before and after the administration of analgesics. This may have led to the registration of some trivial and fleeting episodes of nausea, giving rise to a falsely high incidence of nausea related to pain. Even so, the disappearance of nausea after eighty per cent of the opiate injections is striking. Complete pain relief without relief of nausea is far less frequent ( 9.5 per cent). Conversely, when pain relief is inadequate, nausea persists.

The opiates are often unjustly accused of causing postoperative nausea. This misconception may arise because the presence of nausea with the initial pain is overlooked and the nausea is only registered after the opiate injection, if pain relief is inadequate or waning. Nausea may also make its debut after an inadequate dose of analgesic but can often be abated by achieving optimal pain relief with a supplementary dose.

Opiates may cause nausea and vomiting by sensitizing the vestibular apparatus. ${ }^{4}$ This may be an important factor when the patient becomes more mobile. Our study was done during the early postoperative period when the patients were relatively immobile. An incidence of 3.4 per cent of opiate-induced nausea in the early postoperative period correlates well with a previous investigation. ${ }^{3}$

It is also important to note that a patient who becomes nauseated after an injection of morphine will not necessarily show the same reaction to repeated doses of morphine.

Nausea often accompanies pain in the early postoperative period and can be relieved in a high proportion of cases concomitant with relief of the pain by the intravenous use of opiates in adequate doses.

\section{SUMMARY}

The incidence of nausea in relation to pain was recorded in 104 patients after abdominal operations. Ten per cent of the patients had episodes of nausea not 
related to pain. One hundred and fourteen episodes of concomitant pain and nausea were recorded in 61 patients ( 58.6 per cent).

The intravenous injection of morphine or ketobemidone relieved nausea as well as pain in 80 per cent of the episodes. Relief of pain with persistence of nausea was uncommon and if pain relief was inadequate nausea was unabated.

Nausea was provoked by 3.4 per cent of the morphine injections, but all patients tolerated similar doses of morphine on other occasions without nausea.

Nausea often accompanies pain in the early postoperative period and can be relieved concomitant with the pain by the intravenous use of opiates in adequate doses in a high proportion of cases.

\section{RúsUMÉ}

Après chirurgie abdominale chez 104 patients, on a étudié la corrélation nausée et douleur.

Dix pour cent seulement des patients ont présenté des accès de nausées sans douleur. D’autre part, 114 accès de douleurs accompagnées de nausées ont été relevés chez 61 patients ( 58 pour cent). L'injection intraveineuse de morphine ou de kétobomidone a soulagé la nausée en même temps que la douleur dans 80 pour cent de ces accès. Il était rare d'obtenir un soulagement de la douleur avec persistance de la nausée de même, si la douleur était incomplètement soulagée, il en était de même de la nausée.

La morphine elle-même a été cause de nausées dans 3.4 pour cent injections, cependant tous les patients ont pu en d'autres circonstances recevoir sans nausée des doses semblables de morphine.

La période post-opératoire immédiate est souvent rendue pénible par la douleur et les nausées qui très souvent peuvent être toutes les deux soulagées par l'administration intraveineuse d'un morphinique en doses suffisantes.

\section{REFERENCES}

1. Purkis, I.E. Factors that influence post-operative vomiting. Can. Anaes. Soc. J. 11: 335 (1964).

2. Haumann, J. LeR \& Foster, P.A. The antiemetic effect of halothane. Brit. J. Anaesth. 35: 114 (1963).

3. Andersen, R. Postoperative pain and nausea. Tidsskr. No. Laegeforen. 39: 1368 (1973).

4. Goodman, L.S. \& Gilman, A. The pharmacological basis of therapeutics, Fifth ed., New York, Macmillan, p. 251 ( 1975 ).

5. Jenkins, L.C. \& Lahay, D. Central mechanisms of vomiting related to catecholamine response: Anaesthetic implication. Canad. Anaesth. Soc. J. 18: 434 (1971).

6. Codwin-Austen, R.B. Frears, C.C., \& Bergman, S, Incidence of side effects from levodopa during the introduction of treatment. Brit. Med. J. 1: 267 (1971).

7. Goodman, L.S. \& Gilman, A. The pharmacological basis of therapeutics. Fifth ed., New York, Macmillan, p. 273 (1975).

8. Tigerstedt. Naloxone as narcotic antagonist after balanced anaesthesia. Abstracts. The Twelfth Congress of the Scandinav. Soc. of Anaesthesiologists, Oulu, Finland 11 (1975). 